In 1983, the author wrote a book with T. Kaufman entitled Embryos, Genes and Evolution, which covered some of the same general problems. Raff must have felt that we now know so much more about development that a completely new book was necessary. In the intervening years, developmental biologists have certainly discovered some intriguing primitive features of animal body plans such as the common genes controlling antero-posterior and dorso-ventral axis formation, the eye and heart territories. Three years ago, some of us ventured to call this common constellation of gene expression domains 'the zootype' (see Nature 361, 490; 1993), and the concept does seem to have been strengthened with each new discovery. These results do at least tell us that animals really are monophyletic (that is, they are descended from a single ancestral species), something that has not always been held as self-evident by phylogenetic theorists.

On the other hand, when we come to variation and the origin of derived features, developmental biology still seems unequal to the task before us. We still do not really know what sort of constraints on viable mutational variation are imposed by the developmental programme. We still do not understand the nature of the changes in the programme that have caused particular evolutionary morphological transformations, such as those from indirect- to directdeveloping sea urchins. We still have no idea whether an elephant fly could, as Raff provocatively asks, evolve into an elephant. From this point of view the book, despite its many positive features, may still be somewhat ahead of its time.

Jonathan Slack is in the Developmental Biology Programme, School of Biology and Biochemistry, University of Bath, Bath BA2 7AY, UK.

\section{For whom the net tolls}

\section{Steve Fuller}

Scholarly Publishing: The Electronic Frontier. Edited by Robin Peek and Gregory Newby. MIT Press: 1996. Pp. 363. $\$ 35, £ 29.50$.

INVETERATE 'netsurfers' typically believe that electronic communication has removed all the material obstacles that have traditionally prevented scholarship from enjoying universal access and immediate impact. If you are one of those people, the odds are that your computer is connected to a university or corporate mainframe, which means that you are not directly charged any users' fees and you rarely suffer from delays in transmission.

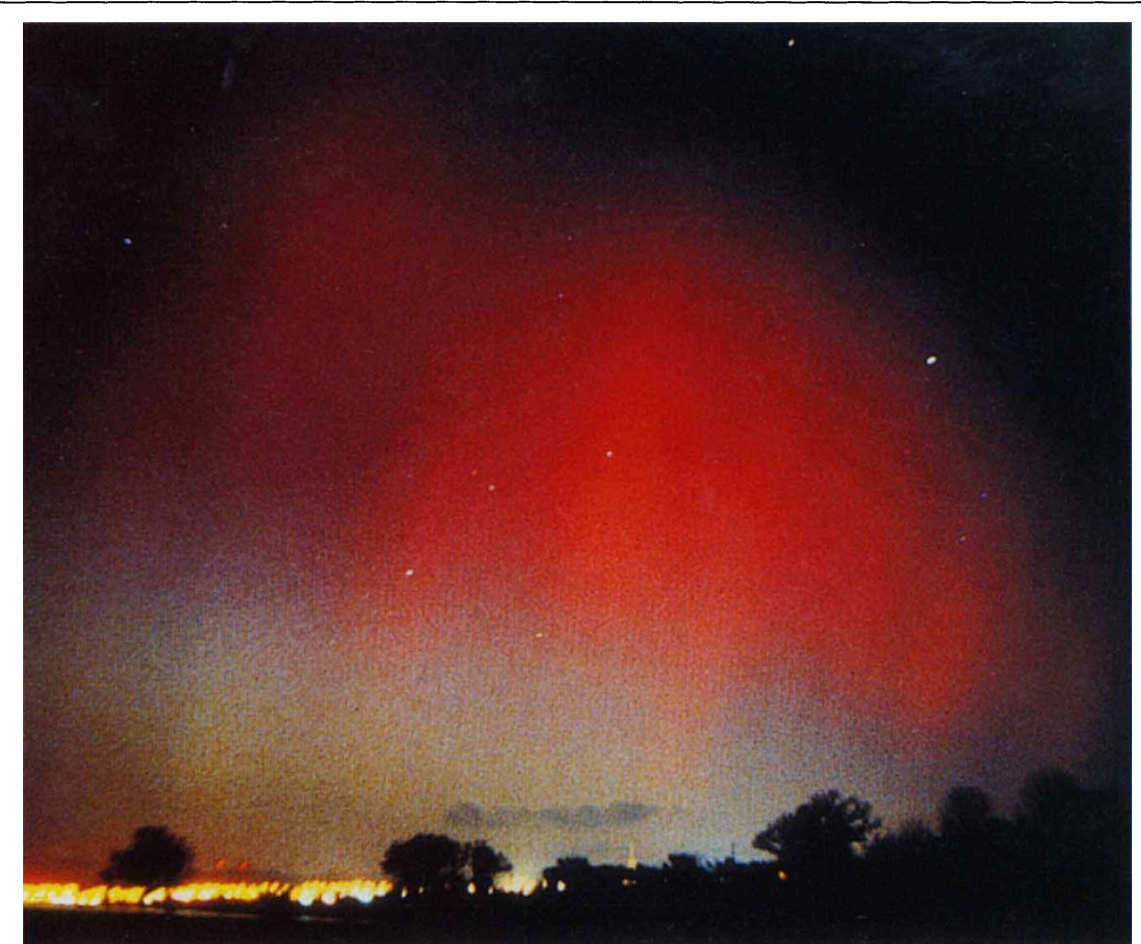

THE major aurora of 24-25 March 1991, visible from the south of England. From the cover of the second edition of The Aurora: Sun-Earth Interactions by Neil Bone (Wiley, $£ 19.99$ (pbk)), which contains a colour mini-atlas of auroral types and forms, descriptions of the different types of aurora, information on related high-atmosphere phenomena and practical advice on auroral observation. For a review of the first edition, see Nature 360, 428 (1991).

However, if you log on through a modem connected to your telephone, the information superhighway' fast loses its reputation for being a frictionless medium of thought. Depending on your location, telephone access fees can mount up very quickly, and the rate structure of commercial electronic carriers may force you into a suboptimal service that frequently suspends your messages in limbo while those of premium customers zip back and forth. Finally, if you are a technophobic scholar lacking connections to a major institution, the Internet merely widens the gap between you and the rest of the intellectual world.

These homely observations provide an anchor in reality for this book's wideranging proposals to embed intellectual life in the electronic medium. About half of the 19 articles project electronic utopias tailor-made for a preferred constituency, usually academics, librarians and publishers. The other half offer more sober and useful analyses of the medium by lawyers, economists and information scientists. Perhaps the best way to read this book is to use the essay by Rob Kling and Roberta Lamb as a guide to understanding the other essays. Kling and Lamb systematically contrast the rhetorics invoked by 'utopian' and 'antiutopian' visionaries of the new electronic age. Kling has recently edited a lively special issue of The Information Society (vol.
11 , no. 4,1995$)$ that manages to get some of the competing visionaries to look each other straight in the eye.

Not surprisingly, the utopians have so far received the most media coverage in their attempt to shape the future of scholarship on the Internet. One imagines them also to be among the inveterate netsurfers. Stevan Harnad, Andrew Olydzko and Ann Okerson clearly fit into this mould; but so too does Jean-Claude Guédon, a literary historian who celebrates the new intensity and crossfertilization that the Internet brings to scholarly communication. As they see it, scholars have a clear sense of what they want and sufficient resources to make it happen, even though a full transition to the electronic medium may incur some short-term institutional costs. The utopians envisage business-as-usual in academic institutions becoming increasingly efficient as scholars are able to access materials and audiences more easily, produce more text and receive quicker feedback. They never consider the congestion problems that will arise as more scholars $\log$ on, nor do they worry much about assigning intellectual property rights to tracts in cyberspace. In fact, there is a tendency among the utopians to blame the publishing industry for anything that reminds academics that their work has an economic dimension.

No such reminder is needed for those 